\title{
Digital Media Literacy to Minimize Narcissistic Personality Disorder as a Cyber Culture (Case Study: WhatsApp Group of Lecturers, Students, and Families)
}

\author{
Anindya Putri Pradiptha ${ }^{1}$, Riri Narasati ${ }^{2}$ \\ \{anindya.putri@budiluhur.ac.id ${ }^{1}$, narasati56@gmail.com² \\ Universitas Budi Luhur, Indonesia ${ }^{1}$ \\ STMIK IKMI, Cirebon, Indonesia ${ }^{2}$
}

\begin{abstract}
The new media Era of communication can be characterizing by the so-called media convergence. The existence of authority in building text and utilizing digital media makes new media users more freely to spread the information. One of the new media that is in the span of seven years is still often used is, WhatsApp. This American-based application presents the ease of usage in a straightforward, unacquainted and userbackground basis. Yet, among a number of advantages and disadvantages, this one social media can cause an effect beyond verbal communication in general. One of the triggers of the effect is sporadic false information dissemination patterns in cyberspace or more commonly known as hoax that then become cyber culture and become the trigger post-war in the real world. In this paper will be described how the nature of WhatsApp, the classification of active users, the difference in response between digital natives and Gen Alfa and its effects, and what causes the user to easily disseminate information that has not been Certainly the reference. This research method is descriptive statistics of Slovin Equation. The case study will be used by WhatsApp Group (WAG), which consists of lecturers, college students, and families. The results found are narcissistic personality disorder (NPD) posed among the social media users. The importance of digital media literacy is the ability that needs to be improved in this era of digital communication to impede the spread of hoax.
\end{abstract}

Keywords: WAG, Digital Media Literacy (DML), NPD, Hoax, Cyber Culture

\section{Introduction}

Internet of Thing, contracted as IOT, generally characterized by the expansion of Internet connectivity that no longer only connects laptops, tablets, or mobile, but also other objects that were originally not used as a communication tool. Everybody gets any data every day. Nowadays people get the information massively, thus the user of a digital application will get too much information. Mostly all digital media share information every time and every day. Anything that people need is already on the future of the digital media tools.

A variety of world information management journals consider the lives of people today will experience hyper connectivity (hyperconnectivity). This circumstance illustrates the conditions when each technology is able to store, analyze, and regulate digital data while connected within the Internet network. With these interfacing intelligence features, automation and interoperability functions (the ability to cooperate) of a technology will be more strengthened. It also affects people to become more dependent and to their smartphones. 
Unfortunately, not all smart phone users can analyze well-received information. Easily they are triggered by the hoax news already goods unsettling the government.

A total of $65 \%$ of the 132 million Internet users in Indonesia believe in the truth of information in cyberspace without rechecking it first [1]. Based on CCSU about the rank of literation in the world in March 2016, Indonesia was on 60th ranking of 61st countries [2]. It means that the interest in reading of Indonesian is still less. That is why people particularly Indonesian will be easier triggered by hoax, because they are less reading. People are not doing the digital media literacy (DML). In the communication world there are known as media literacy, both conventional and digitally. DML will be useful for examining the accountability and truthfulness of an information. This ability is indispensable for anyone who uses the Internet as a container in delivering, receiving, and analyzing information. Even though, President of Indonesia, Mr. Joko Widodo stated that, "Start to do digital literacy from the Families". Beside to upgrade the capacity of citizen in order to face the 4.0 Industry Revolution, the digital media literacy is needed to conquered the fake information and hoax that always spread on the internet.

The existence of authority in building text and utilizing digital media makes new media users more freely to spread the information. One of the new media that is in the span of seven years is still often used is, WhatsApp. This American-based application presents the ease of usage in a straightforward, unacquainted and user-background basis. Yet, among a number of advantages and disadvantages, this one social media can cause an effect beyond verbal communication in general. One of the triggers of the effect is sporadic false information dissemination patterns in cyberspace or more commonly known hoax which then become cyberculture and can trigger post-war in the real world. Even worse is the pattern of NPD being one of the effects that can be unnoticed by users of digital communication media.

In this study, there are 95 respondents who using WAG. The techniques of collecting data by using questionnaire. Not everyone in Indonesia is willing to contribute to being a respondent to a study. Although we have already made a questionnaire in digital form and spread it through WAG and Line, so it can facilitate the respondent when filling it, but in fact it is still an obstacle in collecting the number of respondents. The majority of respondents who have filled digital questionnaires are lecturers and college students.

In a nut shell, Digital Media Literacy to minimize the narcissistic personality disorder as a cyber culture already proof in this study. The WAG members will be realized that a lot of people will dealing with NPD just because they did not do the DML while having some information's from their WAG. Thus, in this study, we will describe what is meant by digital media literacy, cyber culture, and how to minimize the Narsistic Personality Disorder through DML.

\section{Methodology}

The methodology of this study is Descriptive Statistics. Descriptive statistics are part of the science of statistics that only process, presenting data without making decisions for the population. In other words, only see the general overview of the data retrieved. Statistics is a science that learns how to plan, collect, analyze, interpret, and present data [3]. According to Will Kenton, descriptive statistics are brief descriptive coefficient that summarize a given data set, which can be either a representation of the entire or a sample of a population [4]. Population assumes 1000 members by using a Slovin Equation (1960) with margin of error 10\% [5].

The subject of the research are lecturers, college students (colleges), and families. The object is narcissistic personality disorder. The tool is WhatsApp Group. The instrument of this 
study is using questionnaire. The analysis techniques are collecting the data by using digital questionnaire (Google Form) to collect the data of the respondent, counting it by using Slovin Equation, and analyzed the data. The procedure of this research is as below:

a. The questionnaire consists of 22 questions

b. We use Google Form to get the data

c. By using Slovin Equation (1960)

$$
\mathrm{n}=\mathrm{N} /\left(1+\mathrm{Ne}^{2}\right)
$$

Where:

$\mathrm{n}=$ Number of samples

$\mathrm{N}=$ Total population

$\mathrm{e}=$ margin of error

d. $\mathrm{N}=1000, \mathrm{e}=$ margin of error $=10 \%, \mathrm{n}=$ number of samples. Counting with Slovin Equation we have the number of samples is 91 respondents and we analyzed 95 respondents.

e. The data is analyzed with Descriptive Statistics.

\section{Findings and Discussion}

\subsection{Discussion}

\subsubsection{The Data Result}

a. The respondents are 95 people

b. Respondents by gender

Table 1. The gender of the Respondent

\begin{tabular}{lll}
\hline Male & Female & Total \\
\hline $51,6 \%$ & $48,4 \%$ & $100 \%$ \\
\hline
\end{tabular}

From the table above, its shown that male is more dominant as the respondents of this study.

c. Respondent Ages

Table 1. Respondent Ages

\begin{tabular}{ccc}
\hline Ages & Number & \% \\
\hline $18-22$ & 14 & 15 \\
$23-27$ & 8 & 8 \\
$28-32$ & 8 & 8 \\
$33-37$ & 3 & 3 \\
$38-42$ & 3 & 3 \\
$43-47$ & 3 & 3 \\
$48-52$ & 53 & 57 \\
\hline Total & 95 & 100 \\
\hline
\end{tabular}


From the table above, its shown that $50 \%$ of the respondent ages are around 48-52 years old. It means that the maturity of the respondence while comment the message of information or hoax news, wisely.

\section{d. Respondent Education}

Table 3. Respondent Education Background

\begin{tabular}{lc}
\hline \multicolumn{1}{c}{ Education } & \% \\
\hline Senior High School & 11 \\
College Student & 13 \\
Bachelor & 19 \\
Master and above & 57 \\
\hline Total & 100 \\
\hline
\end{tabular}

There are $57 \%$ of the education background of the respondents that already got Master degree and above. This evidence of how the WAG members reacted wisely of some information or hoax news through the broadcasting message in WAG. The proper education will be affected to the WAG member when they shared or commented the news of the forum.

e. Respondent Occupation

Table 4. Respondent Occupation

\begin{tabular}{lc}
\hline \multicolumn{1}{c}{ Occupation } & \% \\
\hline House Wife & 5 \\
Senior High School's Student & 4 \\
College Student & 11 \\
Jobless & 4 \\
Freelancer & 1 \\
Entrepreneur & 1 \\
Civil Servant & 2 \\
White Collar Servant & 1 \\
Factory Workers & 26 \\
Lecturer & 45 \\
\hline Total & 100 \\
\hline
\end{tabular}

Based on the data above, almost $50 \%$ of the respondent's occupation as lecturers. That is why the response when they accepted some information or hoax news on WAG can be comment positively and politely. Only some of them will response negatively, it depends on the discussion of the WAG forum.

a. The percentage of respondents who joined in WAG $100 \%$.

b. Percentage of respondents using WAG more than two are $97 \%$.

c. The level of reading news in WAG $76 \%$, and $24 \%$ does not often read the news shared.

d. The user of respondent number of respondents who read the news in WAG carefully as much as $61 \%$ and $39 \%$ for the rest who are careless.

e. The majority of messages who followed by the respondents are informative news $62 \%$, followed by $21 \%$ of humor, inspiring news $14 \%$, the rest is news related to religious matters $3 \%$ (total 100\%). 
f. Respondents who are included in the active reader type as much as $56 \%$, the rest is a passive reader as much as $44 \%$.

g. The majority of respondents who can find out the type of hoax charged $73 \%$ and the remaining $27 \%$ cannot find out the type of news with hoax content.

h. A total of $91 \%$ keep the news for themself, the rest who shared the news are $9 \%$.

i. After sharing the messages which is opinion about something else those are different responses between WAG member. There are $66 \%$ of WAG members who disagree with this opinion and the rest are $34 \%$ will never give any opinion.

j. The attitude chosen by the majority of respondents is wise in responding to the disagreements (82\%), 14\% leave it alone, the rest will help if there is a difference of opinion that is considered correct and only a few respondents responded with emotions in case of fierce debate.

k. The response of people who inform to others to let them know about hoax news are $80 \%$ and the rest $20 \%$ do not care the messages whether its hoax or not.

\subsubsection{Digital Media Literacy (DML)}

In this era of fast-paced and very easy to get and share information, digital media literacy (DML) is very necessary to implement. DML is useful for fighting false information and hoax news on the Internet. Reported from the media Kompas.com, in January 2018, about $65 \%$ of the 132 million Internet users in Indonesia believe in the truth of information in cyberspace without rechecking it first. The hoax news was easily spread according to Daniel Kahneman, the distribution of the 2002 Nobel economy under the title "Thinking, Fast and Slow" [1].

The importance of DML or better known as tabayun (in Arabic) makes it easy for internet users particularly for the WAG members to check the accountability and the correctness of an information. This is an essential competency that is a must-have and mastered by the WAG members. DML is important to do, so people will be more careful to share the information. In this study, its shown that $80 \%$ of the WAG members already do the DML. They already know the fake information or hoax news, so they will let others know about it. In addition, there are $91 \%$ of WAG members who keep the messages by themselves if they know it's about the hoax news.

According to the result of the questionnaire data, there are $56 \%$ of active readers who usually gives their comments. There are $44 \%$ of the WAG Members who comments positively about some information that shared on the WAG. The traits of a WAG are specific, it depends on the necessary. As an illustration, in WAG college students the content is mostly only information about the matters relating to the lectures, such as Lecture's schedule, lecturer attendance, about the task, examination, etc. Unlike WAG the lecturers, the contents surrounding liability of the lecturers, for instance, announcements about seminars, discussing academic affairs, papers, curriculum, and so on. Quite different than WAG of college students and lecturers, the information that given on the WAG Family is more varied. The information such as informative news, inspirational stories, religious things, family affairs, and which is usually quite in demand is related to humor. 


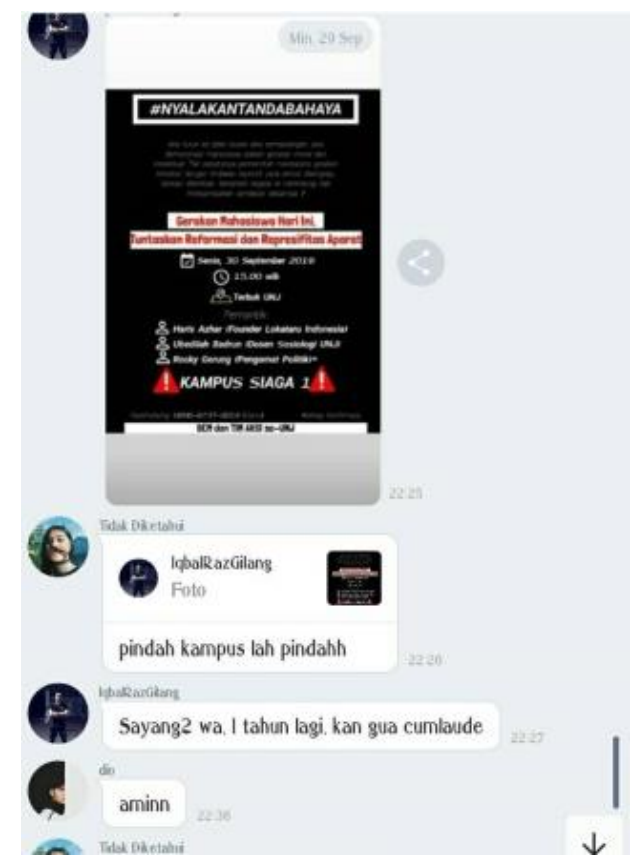

Fig. 1. Conversation in a group of college students about the invitations to join demonstration.

In Figure 1 shows an indifferent student attitude towards a demonstration call. Just remember, the demonstration event is almost simultaneously done by Indonesian college students who reject the BILL or draft that made by the DPR RI 2019. The solicitation to do demonstration was delivered quickly on social media, making it easy for college students to access information. Almost of all college students in Indonesia was not understood about the aspirations that would be delivered on that event. Some of them though it was unnecessary and some of them is common thing for them. In fact, many of the college students do not want to participate in the demo because they choose to join the class. Yet, because of the provocation there were also a lot of college students who finally participated in the demonstration for the reason of 'solidarity' or just followed it and one of them was said, "It's cool". Based on that example, we can assume that actually the college students were already do the DML. They are unsullied to the hoax news or provocative news. If it is attributed to the sheer amount of news that is not shared, surely the purpose of the respondent is to find out the truth of the information/news that is shared.

If we already discuss about the case of the college students, the figure 2 below is the case from the WAG lecturer. It is show that the implementation of DML occurs because the age of majority of respondents is 30 years and above, their educational background is post graduate, and has a job as a lecturer. These points are indicating the level of respondent in sharing the news to WAG. For the age of 30 years and above is a well-mature age, so it will not react more. Of course, they do not want to be sanctioned from the information and electronic transaction law (ITE law) Number 11-year 2008. The following image is an example. 


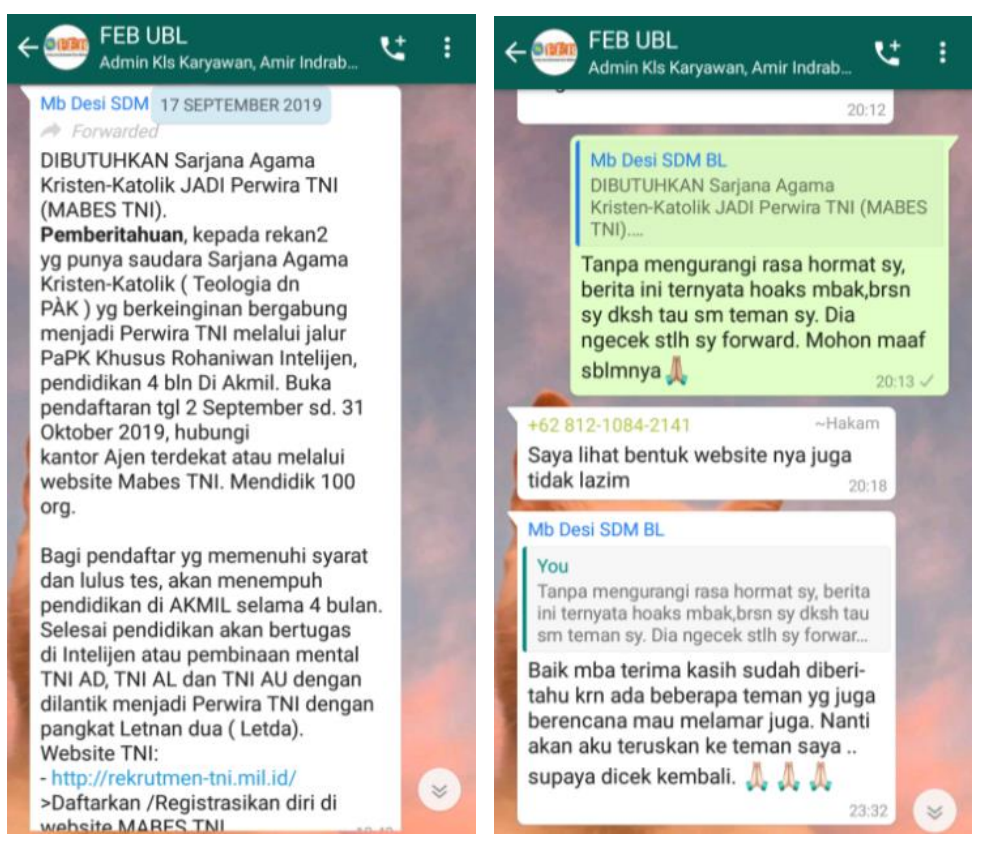

Fig. 2. Positive Feedback If there is a hoax news.

Their occupation is lecture. As a lecturer they must have an intellectual attitude in order their response is more wisely. Almost of the lecturer will not just shared the information without filtered, and some of them will not be angry directly if there are some sarcastic questions. This is because they often get questions or input from college students when teaching. So, if anyone gives comments whether they are positive or even negative they are responding it commonly, because the difference of opinion is a commonplace.

Wisely in dividing or responding to news/information in WAG shows DML is running very well. Compared to the number of Internet users as much as 132 million it is indeed the number is not significant compared to the number of respondents who are as many as 95 people. However, $82 \%$ of the number of respondents have shown that they can respond wisely about the dissemination of information/hoax news in WAG. This means that DML has been done to reduce the spread of hoax and false information.

Here is a sample conversation in WAG lecturer for the wise respondents when there are others in the WAG who convey the truth about the news that is shared. In the conversation, one of the members of WAG shared an article about Arnold Schwazenegger who was an actor and once served as one of the California governors uploaded a photograph of himself who was sleeping under a bronze statue of him in one of the hotels by writing the caption "How Times Changed". The fear or ambiguity is spread over the course between images and articles, but there is one member in the WAG lecturer who explains the truth of the article. The response from other members of the WAG also seemed thoughtful. Their educational background shows that they are seeking the truth of the information first, either when sharing information or responding to information provided. 


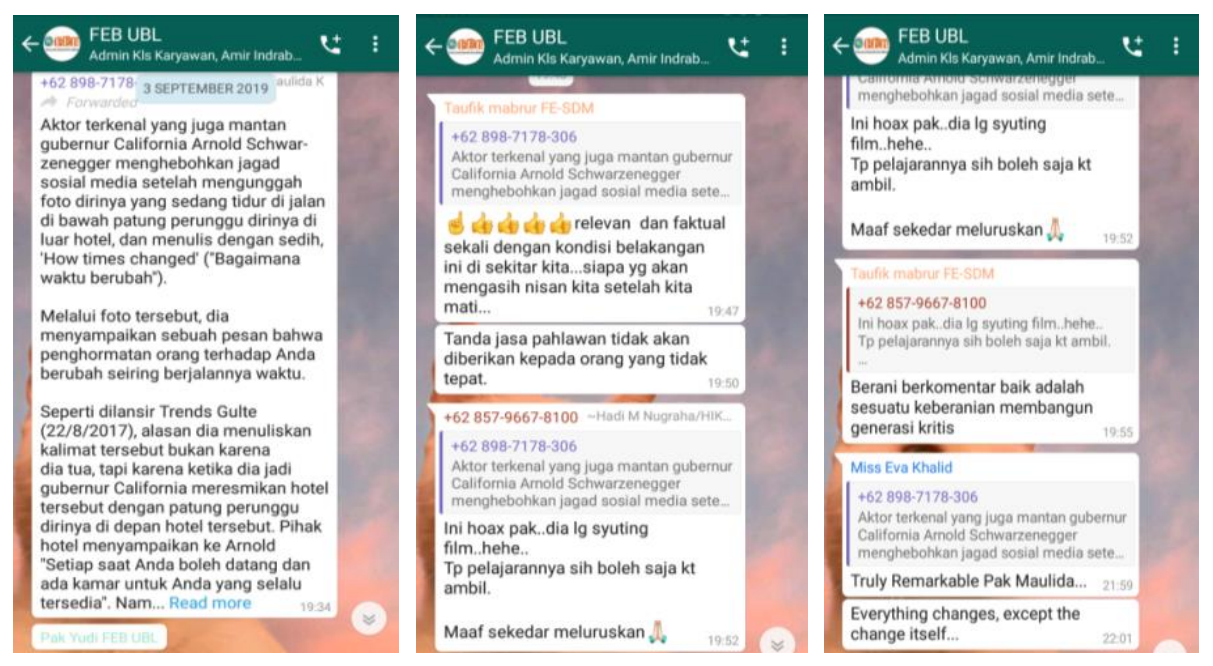

Fig. 3. The wise response from recipient news/information at WAG Lecturer.

\subsubsection{Cyber Culture}

Cyber culture as a new culture has already been believed to be a part of real culture. It is becoming a common concern. It needs openness as well as discussions in the public space to produce norms that can follow the development of the era in this sophisticated technological era. The Internet of Things (IOT) makes its users have some shifting cultures in the real world, this is called a new culture, cyber culture.

The shock culture of cyber culture makes Internet users particularly the WAG member unable to accept the changes in the real world, because some of them will give any comment as they want. The bad side is if the WAG member gives impolite comments. Since the people who always gives impolite comments will cause some conflict, commonly known as post-war. Cyber culture is a form of self-construction for visual identity that has undergone the results of the construction. Just like what has existed long before the technology interferes with human social life. This culture will be the prevailing norms such as what can be done or should not be done in this new culture.

Excerpted from the article titled Cyberculture by Nitrosadagani,

Technology culture through the emergence of cyber culture allow articulation of identity is no longer a space where 'subjectivity' is subject to 'collectivity' as it takes on our 'physical space'. (Donna Harraway 1989, 2003) explained that the development of information technology through the Internet is not merely the transformation of technology but the transformation of culture in which it contains a new ideology that is technology Machine elements that adapt and broaden the reach of our physical presence the machine itself is actually us, we ourselves are moving it, and hence our embodiment (embodiment); The machine is not something that is mechanically and fully mastered us [6].

Still in a similar article, David Bell CS, 2007, defines cyberculture is "a way of thinking about how people and digital technologies interact, how we live together" [6]. Bell clearly states 
that cyber culture is as a way of thinking about how people and digital technologies interact, how humans can live together. Bell's thinking framework is precisely more specific where virtual space is utilized among individuals as a container to discuss how they meet the needs of life.

Bell's opinion of course is well-intentioned, unfortunately the condition is often not in accordance with reality. Internet users especially in WAG are often deviated from the name of the pattern of communicating. The pattern of communicating by text is simply to pour out without the ethical ethics. As in the article published by Merdeka.com, President Joko Widodo, confirming the advancement of digital information technology that is very fast to be balanced by moral standards. Not only that, he said, it is also necessary high ethical use.

The disputes that occurred in the WAG seemed to forget the manners of rebuke or to give criticism to others. Even in the WAG forum, the member does not stare directly, but will be able to create opinions that could not conform to the truth. People who do not know to be seated will be able to have a very easy to be involved even give a different opinion if what is discussed in the WAG is a nature of ignite emotions. Al-Imam Sulaiman Al-Khawas (may Allah have mercy on him) said, "whoever rebuked his brother when they were only the advice, and whoever rebuked his brother in front of many people, then he had the barley of his brother". So, you should be able to speak even though the WAG forum should be considered. Do not let the bad cyber culture impact to be the post-war. The examples are as follows.

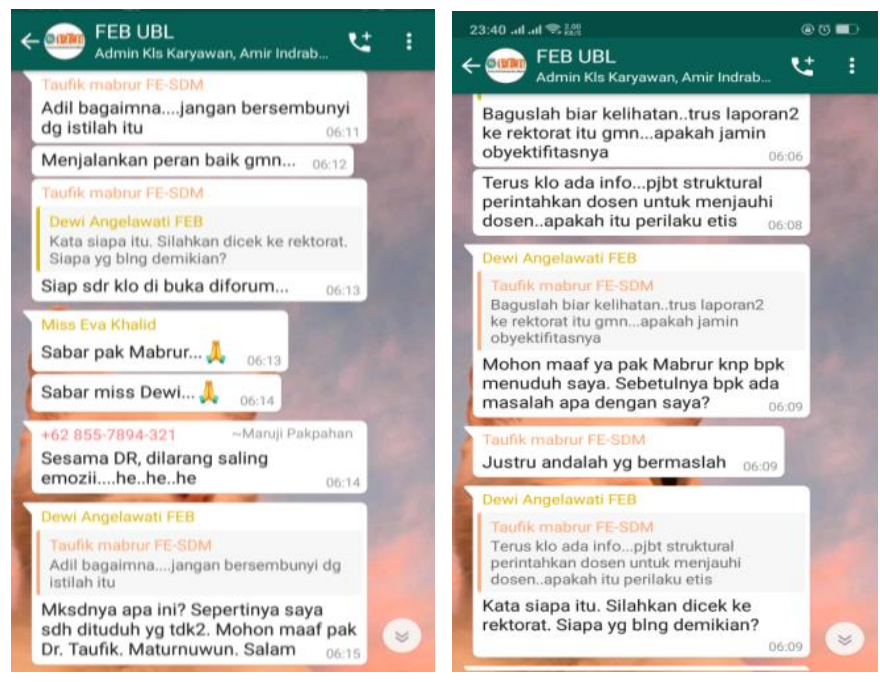

Fig. 4. Negative response of WAG member.

A male lecturer expressed his opinion, inclined towards the other colleagues ' comrades. The lecturer accused one of his colleagues on the forum, which could not all members of the WAG understood about their personal problem. So, people who do not know before, become aware of, and can have a negative impact on the colleague. This negative response is considered a bad cyberculture, where the audience knows the corruption of someone which is unknown the truth about it, just because of the subjectivity of someone who does not like the colleague.

Something is always created paired by God. If there is a negative cyber culture, of course, there is a positive nature. The tendency of positive cyber culture usually occurs among WAG family. The nature and attitude of care that makes them always provide a positive vibe. Just 
greet and give a spirit in the morning alone has made a happy, although only in cyberspace. Like the following example.

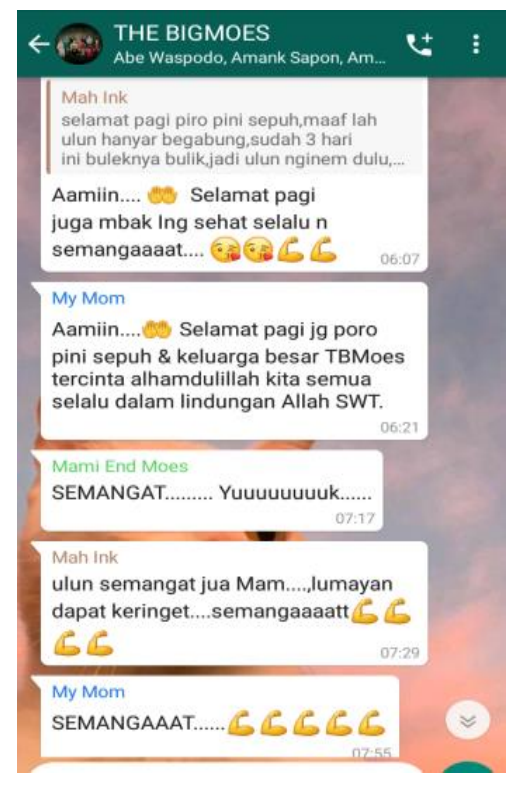

Fig. 5. Positive Cyber Culture.

\subsubsection{Narcissistic Personality Disorder (NPD)}

Narcisse's and or narcissism are the terms that originated in Greek mythology, Narcissus. Narcissus is proud of himself and his pleasure in himself he deeply loves himself. The bad thing happened to her that caused her to be cursed until she loved her own shadow. This very exaggerated flavor made her sink into the pond while she was seeing and the spontaneous one stuck her hand to her reflection [7].

In this sophisticated era, internet users are often exaggerated in responding something. The purchase of sophisticated gadgets is not only a necessity for its functionality, but rather to existing features. For example, someone who buys super-sophisticated gadgets is a good camera for photos, especially selfie photos. The person will be more frequent in the public at any time and in any situation, even if the college students who are studying in the class remain a selfie. Of course, this became a new culture especially among young people or mothers of slang.

Narcissism is often regarded as a cultural and social problem. The unassuming of some experts considers narcissism to be one of the three main traits of personality disorder (the other two are psychopathy and Machiavellianism). It is necessary to understand also that this is not the same as egocentrism [7].

Jealousy and unhealthy competition can trigger narcissism. Narcissism is more referring to domination involving hubris. The tendency to not receive criticism is usually the ones that are often faced for narcissi's. The selfies will try to prove that he is the most correct, so he will go through various ways to knock his opponent in order to look superior.

Related to this paper. Some of the respondents who react positively there are also negative. What to realize is that both reactions arise after they upload a news/information to WAG, then 
the member of the group commented on what has been shared by the sender/information. The reactions that arise afterwards sometimes make researchers feel funny, whether or not aware of the archives of the sender of the news that was sent can refer to the NPD. Where a sense of delight or anger arises over news or information that they are not themselves making, but only copying it back and spreading it. Remember the sender is not the original ' author ' of the article, it's just a 'part-time Courier'.

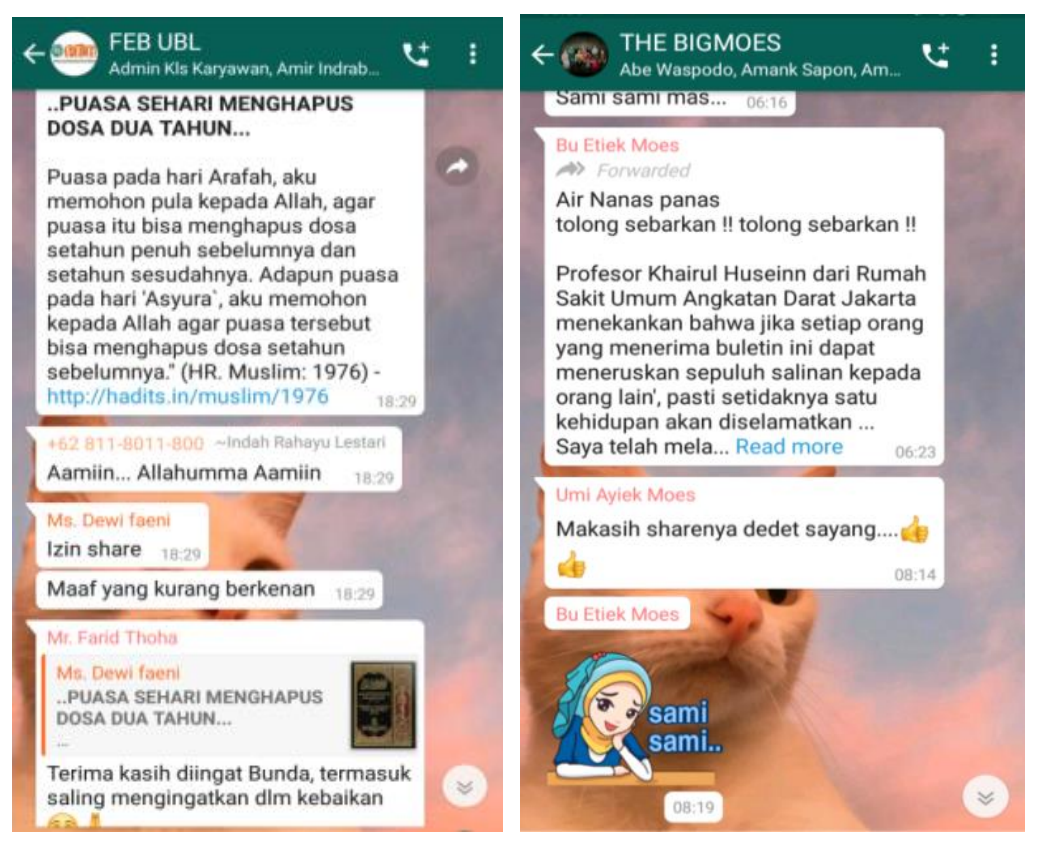

Fig. 6. Happy response after sharing an information/news.

If the above is an example of a conversation in WAG for the respondents who react positively then the example below is an example of a negative reaction of one of the newscasts who does not receive when someone else in the WAG is in the do DML. WAG is a dance workshop that consists of lecturers, employees, and college students. Neither the sender nor the one who responded was a lecturer. The information sender is about 40 years old and only became a lecturer, while the Candide is 30 years old and has become a lecturer for the first year. Seen the negative reaction shown by the news sender even though it has been logically explained by other users. This kind of criticism Model in the world of psychology can lead to one of the features of NPD. 

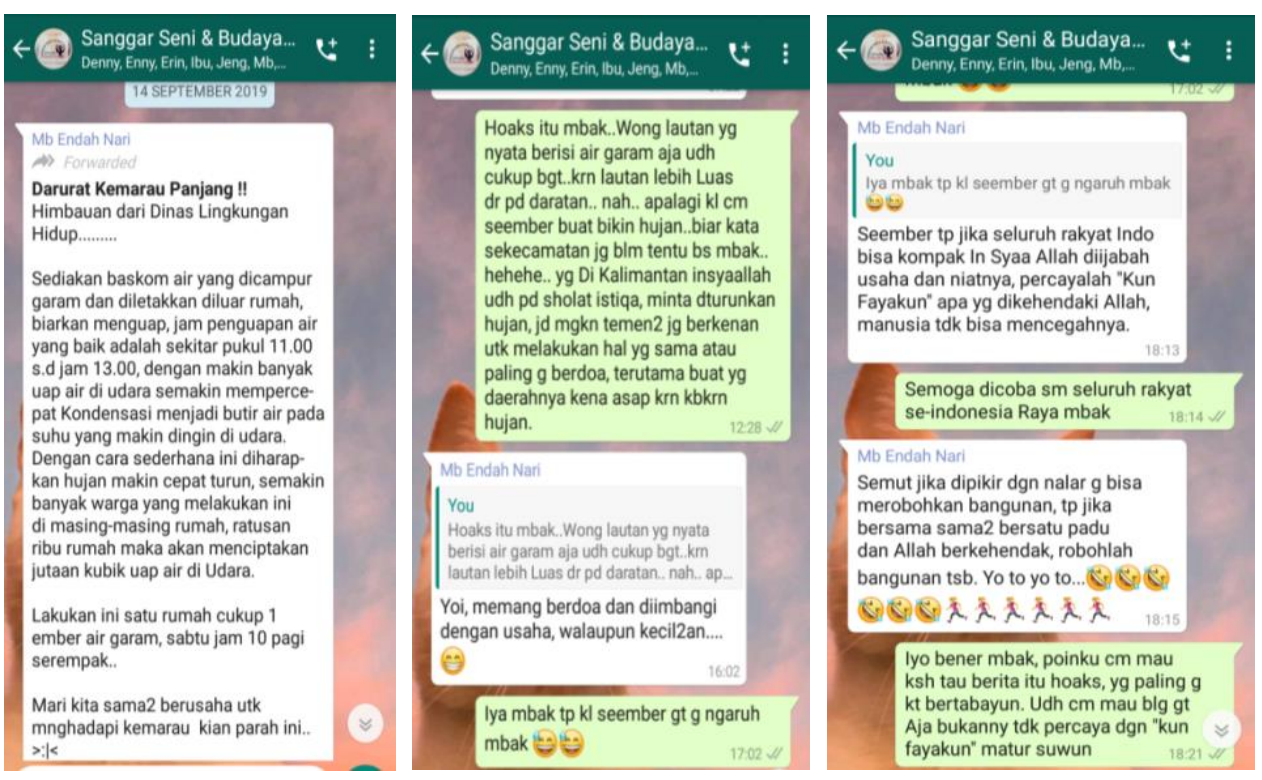

Fig. 7. Negative response after sharing information/news.

Picture 7 above discusses the information about the appeal of the Environment Office (even though not necessarily from this party who made the information) to provide a bucket of water mixed with salt, then put in front of the porch House Each citizen. The sender gets this chain message from another WAG, because the researcher who is also the person who responds that the news contains a hoax element, also get similar news on the same day. So are the other associates. The sender feels offended by the exposure of the person responding to the news. has been described logically about the he dealt with the intention not to trust a news without finding out the truth first. It's funny again what causes the newscast to be offended when he just sends it, not the one who makes the news. The sender insists that there is truth in the article he dealt, even after the response from the group members who explain that the news contains fake news content.

Both positive and negative response from the respondents, it is not possible to conclude that they have NPD. However, such a tendency should be left to culture, which is not good in the real world. One is a way of being and addressing something excessively which is not the result of his own work.

\subsection{Findings}

a. There is only a little amount of NPD in WAG members, particularly in WAG of lecturer and family.

b. The WAG member is able to differentiate the fake information or hoax news.

c. The WAG member give comment in polite and impolite manner.

d. The respondents who directly share news to other WAG or others as much as $26 \%$, while not sharing them directly $74 \%$. 


\section{Conclusion}

Based on the above exposure, it can be concluded:

a. DML is the most recommended way to fight false information and hoax news, including hate speech, etc. In this study most of the respondents have implemented DML patterns in the WAG forum. Age's maturity, educational background, and profession are very affecting the matter.

b. Cyber culture is a real-world culture that is then converted into cyberspace. The shift in communicating cultural patterns that cause divisions in cyberspace is often inevitable to the real world. Differences in the WAG forum are commonplace, although sometimes the way of delivery is not according to the etiquette and the prevailing norms in the community. The lack of understanding in the WAG forums can be impactful in real life too. Post-war is not only happening in the virtual world, but it can continue in the real world as well. The need to do digital literacy to minimize the cyber culture that can lead to NPD.

c. The way to minimize NPD is to be more prudent in addressing something. The positive response that needs to be built in yourself will certainly reduce one of the diseases of this mental disorder. Applying DML pattern as a cyber culture can be an alternative to preventing NPD.

\subsection{Recommendation}

a. The WAG member should open mind to minimize the NPD.

b. Educate the rest of WAG member to minimize the member who still believe in hoax news.

c. Educate the rest of the WAG members who still gives their impolite manners.

\section{References}

[1] N. Tashandra, "Menkominfo: Mulailah Literasi Digital dari Keluarga," Kompas.com, 2018. [Online]. Available: https://lifestyle.kompas.com/read/2018/01/30/193015920/menkominfomulailah-literasi-digital-dari-keluarga.

[2] D. Damarjati, "Benarkah Minat Baca Orang Indonesia Serendah Ini?," Detik News, 2019. [Online]. Available: https://news.detik.com/berita/d-4371993/benarkah-minat-baca-orangindonesia-serendah-ini.

[3] Fin Statistics, "Pengertian Statistiks Deskriptive," Fin Statistics, 2013. .

[4] W. Kenton, "Descriptive Statistics," Investopedia, 2019. [Online]. Available: https://www.investopedia.com/terms/d/descriptive_statistics.asp.

[5] T. M. Amirin, "Populasi dan Sampel Penelitian 4: Ukuran Sampel Rumus Slovin," 2011. [Online]. Available: www.tatangmanguny.wordpress.com.

[6] Nirogasadagani, "Cyberculture," $2014 . \quad$ [Online]. Available: https://nirogasadagani.wordpress.com/2014/07/02/cyberculture-2/.

[7] A. Quamila, "Bedanya Narsis dan Narcissistic Personality Disorder," hellosehat.com, 2017. [Online]. Available: https://hellosehat.com/hidup-sehat/psikologi/beda-narsis-dengannarcissistic-personality-disorder/ . 